\title{
Correlation between Sociophysiological Profile and Working Posture of Rural and Urban Women
}

\author{
Nikhat Parveen $^{1} *$, Shishir Kala ${ }^{1}$ and Richa Kumari ${ }^{2}$ \\ ${ }^{1}$ Department of F.R.M. C.C.Sc. Pusa, Samastipur-848125, India \\ ${ }^{2}$ Department of H.E.C.M.C.C.Sc. Pusa, Samastipur-848125, India \\ *Corresponding author
}

\section{Ke y w o r ds \\ Sociophysiological profile, Working posture, Rural and urban women \\ Article Info \\ Accepted: \\ 15 February 2020 \\ Available Online: \\ 10 March 2020}

\section{A B S T R A C T}

Ergonomics analyses the relationship between the human body and the objects we use and the spaces where we live and work in order to optimise movements and avoid unnatural postures that could be harmful to our health. An Indian woman spends on an average 5-6 hours in her kitchen which may amount to approximately one fourth of her life span. In the traditional Indian kitchen, due to unawareness of ergonomics women's usually performed the various kitchen activities works was usually in a prolonged squatting posture and sitting on patra or pihri which used to pose a number of health hazards. Since sitting requires the muscles to hold the trunk, neck and shoulders in a fixed position and a fixed working position squeezes the blood vessels in the muscles reducing the blood supply to the working muscles just when they need it the most. An insufficient blood supply accelerates fatigue and makes the muscles prone to injury. Such problems can be minimized the stress and fartique on part of workers through with the use of ergonomics which can increased the work effectiveness in kitchen. Keeping in view of these rational in mind the study was conducted in Muzaffarpur District of Bihar State. The main purpose of this study research is to know the coefficient of Correlation between Socio-physiological profile and working posture of rural and urban women. The analysis of results indicated that in rural area age of $(0.236)^{*}$ respondent's occupation $(0.255)^{*}$ type of family $(0.235)^{*}$ etc were founds to be negatively significant at $5 \%$ level of probability and type of kitchen $(0.208)^{*}$, was founds to be significant at $5 \%$ level of whereas anthropometric measurement i.e. heart rate $(0.447)^{*}$ was calculate to be negatively significant at $5 \%$ level. While in urban area independent variable i.e. Age $(0.217)^{*}$, Type of family $(-0.267)^{*}$, size of kitchen $(0.352)^{*}$ etc. came to be negatively significant at $5 \%$ level and anthropometric measurement of respondents i.e. height $(0.596)^{* *}$ was found to be highly significant at $1 \%$ level of probability. Finally it was observed that height was found to be the most important anthropometric dimension which affects in ease of cooking activity to be performed by the women. 


\section{Introduction}

Ergonomics analyses the relationship between the human body and the objects we use and the spaces we live and work in order to optimise movements and avoid unnatural postures that could be harmful to our health. An Indian woman spends on an average 5-6 hours in her kitchen which may amount to approximately one fourth of her life span.

The kitchen is one of the important areas of a house, which could be the applications of the most benefits from ergonomics. It ensures ease of use and allows to move comfortably in the space based on physical requirements and habits. In the kitchen, there is need to have everything on hand to move freely and tirelessly is often the goal which is not achieved satisfactorily by women. Repetitive movements for various activities like chopping and dicing vegetables, awkward positions like holding the head downward to cook food or bending while arranging utensils overreaching like reaching for supplies on platform or reaching for higher cabinets lifting like moving pots and pans are the most commonly done while working in kitchen.

In the traditional Indian kitchen, works are usually done in a prolonged squatting posture and sitting on patra or pihri which used to pose a number of health hazards. Since sitting requires the muscles to hold the trunk, neck and shoulders in a fixed position and a fixed working position squeezes the blood vessels in the muscles reducing the blood supply to the working muscles just when they need it the most. An insufficient blood supply accelerates fatigue and makes the muscles prone to injury. Maria Lis et al., in 2007 reported that women sitting posture requires for more than half a workday in combination with whole body vibration and awkward postures, increases health problems i.e the low back pain, sciatica etc. But the problems used to be resolved by frequent changes of posture from sitting to standing to relieve pressure on the back of heels. The problem like difficulty in reaching out to too high shelves in standing type of kitchens also cause health problems as the height of shelf force people to either raise their heels or use patra or stool to reach the top shelf. Tip toeing to reach out top most shelves also increases human costs. Besides this women generally adopt standing, half bending and full bending postures during storing or picking up articles and frequency of changing postures are more in full bending position followed by half bending and standing postures (Joshi, 2006). Kaur et al., (2012) highlighted that forward and side bending are the most frequently used postures while performing kitchen storage activities followed by squatting posture by rural respondents and bending on knees by urban respondents. Chaudhary and Shuku (2007) focused on postures adopted by elder women while using existing storage units in kitchen and reported that majority of the elder women required no corrective measures in their posture while using top and middle shelves of most of the storage units in kitchen because the shelves height below the maximum reach of the respondents, whereas, for lower shelves respondents needed corrective measure in their postures because the height of the lower shelves of the existing storage units below the minimum reach of the respondents leading to adoption of poor posture.

Kaushik and Charpe (2008) suggested that ergonomics helps design workplaces and hence help to reduce stress on the part of the worker.

Keeping into consideration of variations in working posture of women in rural and urban area's kitchen, the study has been planned with the, study has been planned with the following objectives. 
1. To know about correlation between sociophysiological profile and working posture.

2. To know about correlation between sociophysiological profile and kitchen design.

\section{Materials and Methods}

Study was conducted in Muzaffarpur District of Bihar State. Out of which two Blocks namely Bandra Bock and Musahri Block were randomly selected. From each Block Ratwara Village as rural area and Bhagwanpur city as urban area to make comparative study of rural and urban areas kitchen design. Further, 30 female respondents from both the rural and urban areas were selected for conducting research. The various anthropometric data viz. Height, weight, BP, Pulse rate etc. were recorded with the use of appropriate tools and machines.

\section{Results and Discussion}

The result of data in Table 1 Shows the correlation between dependent variable i.e. working posture of rural and urban areas with the selected 24 independent variables. The analysis of results indicated that in rural area age $(-0.236)^{*}$ respondent occupation ($0.255)^{*}$ type of family $(-0.235)^{*}$ etc were founds to be negatively significant at $5 \%$ level of probability, and type of kitchen $(0.208)^{*}$, was founds to be significant at 5\% level of whereas anthropometric measurement i.e. heart rate $(-0.447) *$ was came to be negatively significant at $5 \%$ level. While in urban area independent variable i.e. Age $(-0.217)^{*}$, Type of family, $(-0.267)^{*}$, size of kitchen $(-0.352)^{*}$ etc. came to be negatively significant at $5 \%$ level, and anthropometric measurement of respondents i.e. height $(0.596)^{* *}$ was came to be highly significant at $1 \%$ level of probability.
The analysis of data in Table 2 shows the correlation coefficient between dependent variable i.e. kitchen design of rural and urban areas with the selected independent variables. Kitchen design was taken as dependent variables which co-related with 24 independent variables and the data were taken from both rural as well as urban area's respondent's and their kitchen. The analysis of result revealed that independent variable i.e. Respondent education $(-0.305)^{*}$, Family education status $(-0.227)^{*}$, family occupation $(-0.365)^{*}$, and type of house $(-0.203)^{*}$ came to be negatively significant at 5\% level. Whereas source of water $(0.257)$ was found to be significant at $5 \%$ level of probability. In urban area results indicated that independent variable type of family $(0.204)^{*}$ found to be significant at 5\% level whereas family income $(-0.228)^{*}$ and respondent income $(-0.234)^{*}$ found to be negatively significant at $5 \%$ level and anthropometric measurement of respondent's height $(0.003)$ was came to be negatively significant at $1 \%$ level of probability.

The results of data in Table 3 Showed that the compute value of kitchen design was found to be highly significant at $1 \%$ level of probability. Which indicated that there was significant difference with mean score (1.666) of kitchen design So it can be concluded that the kitchen design of rural and urban area had significant $t$ value.

The results of data in Table 4 highlighted that the difference is the mean score of these two areas were tested for its statistically significant by calculating the $\mathrm{t}-$ value. The data in table 4.12 shows that t value (3.730)** of working posture came to be highly significant at $1 \%$ level of probability there by a significant difference was found in the mean score (186). 
Table.1 Coefficient of correlation between working posture of rural and urban area and selected independent variables

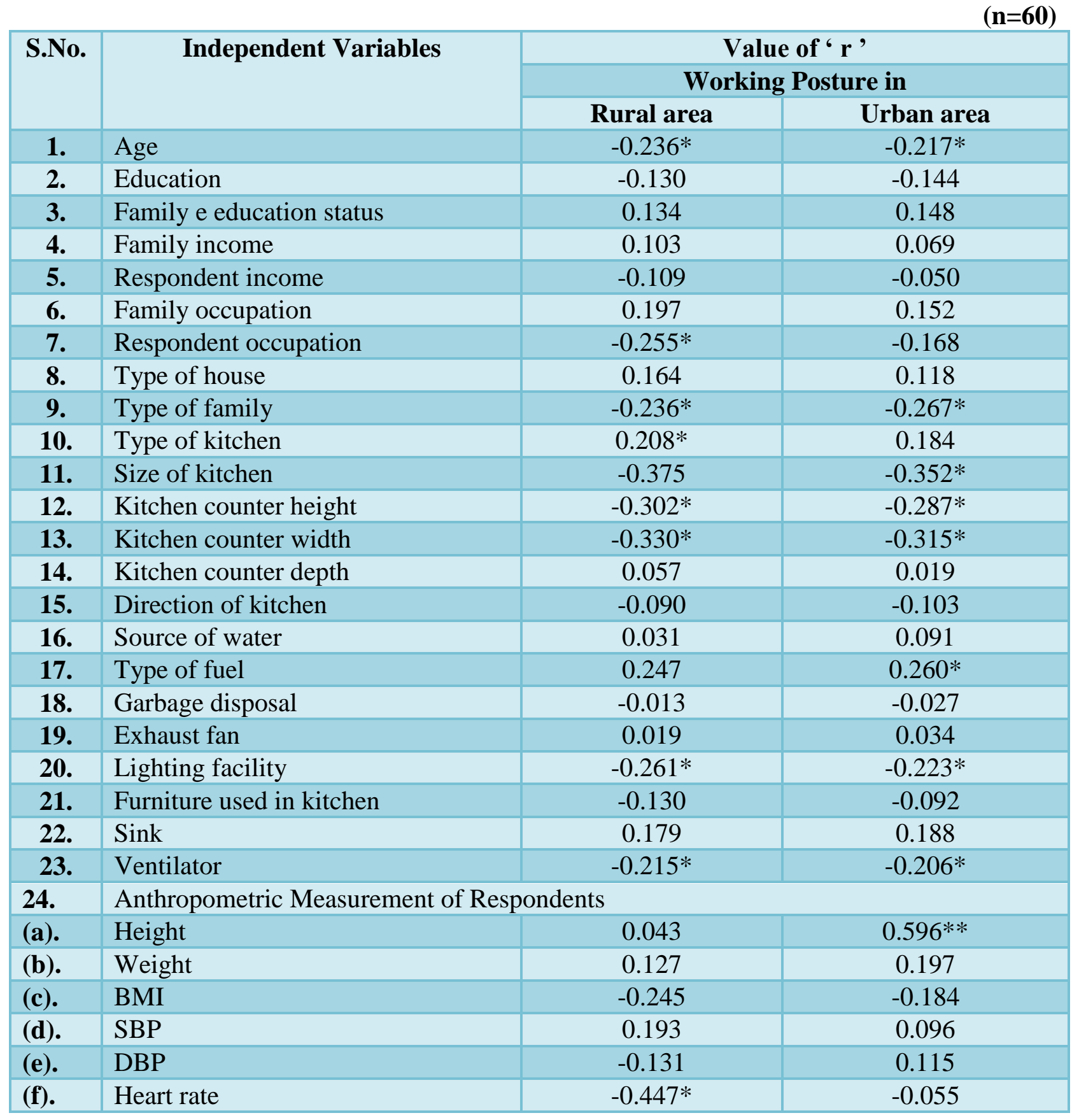


Table.2 Coefficient of correlation between kitchen design of rural and urban area and selected independent variables

\begin{tabular}{|c|c|c|c|}
\hline \multirow[t]{3}{*}{ S.No. } & \multirow[t]{3}{*}{ Independent Variables } & \multirow{2}{*}{\multicolumn{2}{|c|}{$\begin{array}{c}\text { Value of ' } r \text { ' } \\
\text { Kitchen design in }\end{array}$}} \\
\hline & & & \\
\hline & & \multicolumn{2}{|c|}{ Dicten uesign in } \\
\hline 1. & Age & -0.076 & -0.082 \\
\hline 2. & Education & $-0.305^{*}$ & 0.169 \\
\hline 3. & Family e education status & $-0.227 *$ & 0.021 \\
\hline 4. & Family income & -0.162 & $-0.228 *$ \\
\hline 5. & Respondent income & -0.031 & $-0.234 *$ \\
\hline 6. & Family occupation & $-0.365^{*}$ & -0.069 \\
\hline 7. & Respondent occupation & -0.456 & -0.208 \\
\hline 8. & Type of house & $-0.203^{*}$ & -0.025 \\
\hline 9. & Type of family & 0.093 & $0.204 *$ \\
\hline 10. & Type of kitchen & -0.081 & 0.017 \\
\hline 11. & Size of kitchen & 0.091 & 0.128 \\
\hline 12. & Kitchen counter height & -0.139 & 0.127 \\
\hline 13. & Kitchen counter width & 0.039 & 0.100 \\
\hline 14. & Kitchen counter depth & -0.178 & $-0.266 *$ \\
\hline 15. & Direction of kitchen & -0.051 & -0.161 \\
\hline 16. & Source of water & $0.257 *$ & 0.031 \\
\hline 17. & Type of fuel & -0.128 & $-0.256^{*}$ \\
\hline 18. & Garbage disposal & -0.161 & 0.026 \\
\hline 19. & Exhaust fan & 0.116 & 0.073 \\
\hline 20. & Lighting facility & 0.128 & $0.243 *$ \\
\hline 21. & Furniture used in kitchen & 0.164 & 0.105 \\
\hline 22. & Sink & -0.070 & $-0.255^{*}$ \\
\hline 23. & Ventilator & -0.178 & 0.025 \\
\hline 24. & \multicolumn{3}{|c|}{ Anthropometric Measurement of Respondents } \\
\hline (a). & Height & 0.203 & $0.003 * *$ \\
\hline (b). & Weight & -0.248 & -0.029 \\
\hline (c). & BMI & -0.093 & -0.024 \\
\hline (d). & SBP & 0.075 & 0.062 \\
\hline (e). & DBP & -0.131 & 0.064 \\
\hline (f). & Heart rate & 0.314 & 0.157 \\
\hline
\end{tabular}


Table.3 Paired t-test of kitchen design of rural and urban area

\begin{tabular}{|c|c|c|c|c|c|}
\hline $\begin{array}{c}\text { S. } \\
\text { No. }\end{array}$ & $\begin{array}{c}\text { Dependent } \\
\text { Variables }\end{array}$ & Mean & SD & Std Error & T value \\
\hline 1. & Kitchen Design & 1.666 & 1.347 & 0.246 & $6.774 * *$ \\
\hline
\end{tabular}

Table.4 Paired t-test of working posture of rural and urban area respondents

\begin{tabular}{|c|c|c|c|c|c|}
\hline S.No. & $\begin{array}{c}\text { Dependent } \\
\text { Variables }\end{array}$ & Mean & SD & Std Error & T value \\
\hline 2. & Working Posture & 18600 & 27.316 & 4.978 & $3.730 * *$ \\
\hline
\end{tabular}

** Significant at $0.01 \%$ level of Probability

It could be concluded that height was found to be the most important anthropometric dimension which affects in ease of cooking activity to be performed by the women in the urban kitchen. Types of fuel also affected the working conditions of the women.

Further kitchen design as well as working postures of women was also found to have be significant impacts with sociophysiological profile of women in rural and urban areas.

\section{References}

Chaudhary N and Shukul M (2007). Posture adopted by elder women while using existing storage units in kitchen. Proc Humanizing Work and Work Environment (HWWE). Pp 56. Central
Institute of Agricultural Engineering, Bhopal, India.

Joshi P (2006). A study on biomechanical problems of homemakers relating to existing storage spaces in the houses. M.Sc. Thesis, Punjab Agricultural University, Ludhiana, India.

Kaur S, Kaur H and Sidhu M (2012). Postural difficulties faced by women while performing kitchen storage activities. Asian J Home Sci 7:428-430.

Kaushik, V. and Charpe N.A (2008). Effect of body Posture on stress Experienced by Worker, College of Home science, MPUAT, Udaipur, Rajasthan, India

Maria Lis A, Black K M, Korn $\mathrm{H}$ and Nordin M (2007) Association between sitting and occupational LBP. European Spine $J 16: 283-298$.

\section{How to cite this article:}

Nikhat Parveen, Shishir Kala and Richa Kumari. 2020. Correlation between Sociophysiological Profile and Working Posture of Rural and Urban Women. Int.J.Curr.Microbiol.App.Sci. 9(03): 2077-2082. doi: https://doi.org/10.20546/ijcmas.2020.903.238 